\title{
Quantitative Determination of Glycerol in Antarctic Krill (Euphausia superba Dana) by High-Performance Thin-Layer Chromatography
}

\author{
Xiangning Han and Daicheng Liu* \\ Key Laboratory of Animal Resistance, College of Life Science, Shandong Normal University, \\ 88 East Wenhua Road, Jinan 250014, P.R. China
}

Received: 07 April 2017; accepted: 25 May 2017

\begin{abstract}
In this reported study, a direct high-performance thin-layer chromatographic (HPTLC) method was developed to qualitatively detect and quantitatively determine glycerol in Antarctic krill for the first time. This procedure was based on the extraction of glycerol by ultrasonic solvent extraction with anhydrous ethanol, silica-gel column chromatographic separation, HPTLC detection and quantification using methylene chloride-methanol $(5: 1, \mathrm{v} / \mathrm{v})$ as the developing solvent and alkaline potassium permanganate as chromogenic agent. The content of glycerol was $1.3725 \pm 0.218 \mathrm{mg} / \mathrm{g}$ in freeze-dried Antarctic krill. The structure of glycerol in the Antarctic krill was subsequently determined by gas chromatography-mass spectrometry (GC-MS) which verified the presence of the material in the krill. The HPTLC method exhibited excellent accuracy with a recovery of $90.1-103.3 \%$ and good precision with a relative standard deviation (RSD) of $1.59-4.84 \%$. The results clearly exhibited the applicability of the proposed for quantifying glycerol in Antarctic krill.
\end{abstract}

Keywords: Glycerol, HPTLC, Antarctic krill

\section{Introduction}

Glycerol is micromolecular colligative antifreeze that was first found in the eggs of the silk worm, Bombyx mori [1]. Other frigostable insects (such as the beetle Cucujus clavipes) and fishes (such as rainbow smelt Osmerus mordax) have also been found to contain the antifreeze glycerol [2-4]. Glycerol is an essential antifreeze in cold-adapted animals that exhibit extraordinary extensile performance. Antarctic krill, a species of psychrophilic zooplankton, can tolerate and function in the extreme cold environment present under Antarctic ice [5], but there have been no reports of the presence of glycerol in Antarctic krill. Therefore, it was deemed important to develop a process of extraction, cleanup, and detection in an analytical method to detect and quantify glycerol in Antarctic krill.

Nearly all traditional glycerol extraction methods are time- and solvent-consuming, while the extraction yields are often insufficient [6]. One of the powerful tools used for solvent extraction from various samples is ultrasonic extraction, which is simple, time saving, and efficient [7].

Silica gel column chromatography is a simple, fast, and efficient method that is a common method used to refine crude extracts [8].

In recent years, because of low operation cost and high sample throughput, high-performance thin-layer chromatography (HPTLC) has gained greater acceptance as an analytical procedure [7]. Although there are many other possible methods for glycerol analysis (such as fluorescent determination) [9], HPTLC remains a valid, cheap, and simple procedure for qualitative detection and quantitative determination of substances.

The aim of this work was to extract glycerol in Antarctic krill by ultrasound, to detect and to quantify glycerol by HPTLC after refining by silica gel column chromatography and to verify glycerol structure by gas chromatography-mass spectrometry (GC-MS).

*Author for correspondence: liudch@sdnu.edu.cn

\section{Experimental}

Sample extraction. Frozen whole Antarctic krill $^{a}$ ( 200 g) were freeze-dried at $-46{ }^{\circ} \mathrm{C}$ which produced $40 \mathrm{~g}$ of dry Antarctic krill. This dry Antarctic krill was extracted three times with anhydrous ethanol $(1: 15, \mathrm{w} / \mathrm{v})$ by ultrasound ${ }^{b}$ under the conditions of $0.5 \mathrm{~h}, 25^{\circ} \mathrm{C}, 350 \mathrm{~W}, 40 \mathrm{kHz}$. The extracts were combined, filtered, and evaporated ${ }^{c}$ to dryness $\left(25^{\circ} \mathrm{C}\right)$. The residue was dissolved in anhydrous ethanol, and the volume of the mixture was accurately set to $10 \mathrm{~mL}$ (V1). This original sample was used for analysis and refinement.

Standard preparation. Standard solutions of glycerol were prepared by dissolving accurate quantities of glycerol $^{d}$ $(\geq 99.5 \%)$ in methanol. The mass concentration of glycerol was $1.0 \mathrm{mg} / \mathrm{mL}$.

Verifying the presence of glycerol by HPTLC. The developing solvent methylene chloride-methanol (5:1, v/v) was added to the development chamber ${ }^{e}$ and incubated for $20 \mathrm{~min}$. The original sample and glycerol standard were spotted onto an activated pre-coated silica gel HPTLC $\mathrm{GF}_{254}$

\footnotetext{
${ }^{a}$ Frozen whole Antarctic krill was obtained from LiaoYu Group Co., Ltd. (Dalian, Liaoning China); this batch of Antarctic krill (35-50 mm of body length) was caught in the surrounding waters of the Chinese Great Wall Antarctic Station (48.1-48.3 zone in the Antarctic) in the first quarter of 2015. An FUD-1200 freeze dryer was used to prepare the krill and was obtained from Tokyo Rikakikai Co. Ltd. (Tokyo, Japan).

${ }^{b}$ The ultrasonic cleaning machine was obtained from Kun Shan Ultrasonic Instruments Co., Ltd. (Jiangsu, China).

${ }^{c}$ A rotavapor-3 rotating evaporator was obtained from Buchi (Flawil, Switzerland).

${ }^{d}$ Glycerol standard $(\geq 99.5 \%)$ was purchased from Aladdin (Shanghai, China).

${ }^{e} \mathrm{~A}$ development chamber $\left(10 \times 12 \times 5 \mathrm{~cm}^{3}\right.$, consisting of a twin-through glass chamber) was purchased from Shanghai Xinyi Instrument Co. Ltd. (Shanghai, China).
}

This is an open-access article distributed under the terms of the Creative Commons Attribution-NonCommercial 4.0 International License (https://creativecommons.org/licenses/by-nc/4.0/), which permits unrestricted use, distribution, and reproduction in any medium for non-commercial purposes, provided the original author and source are credited, a link to the CC License is provided, and changes - if any - are indicated. 


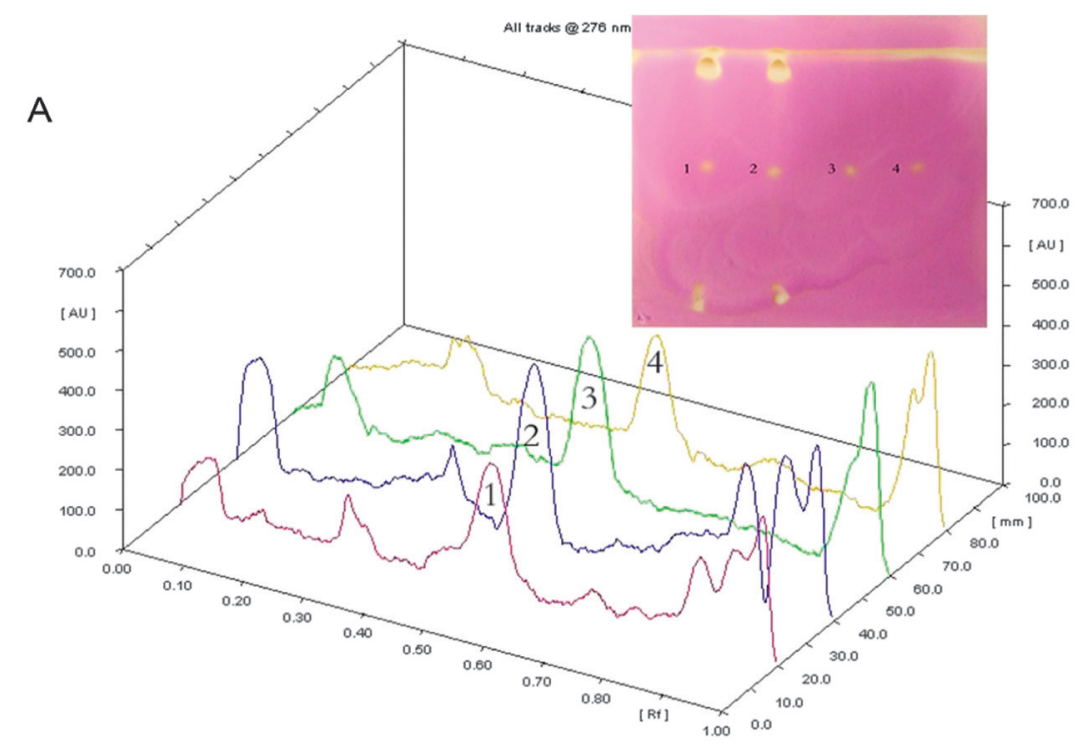

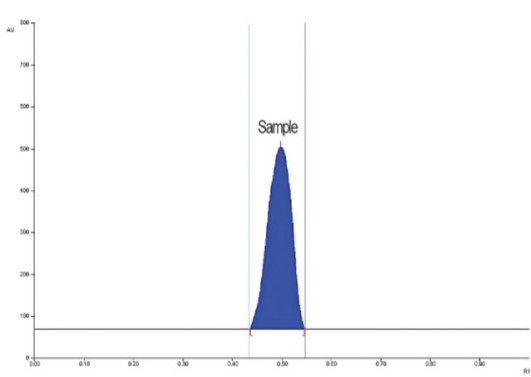

B

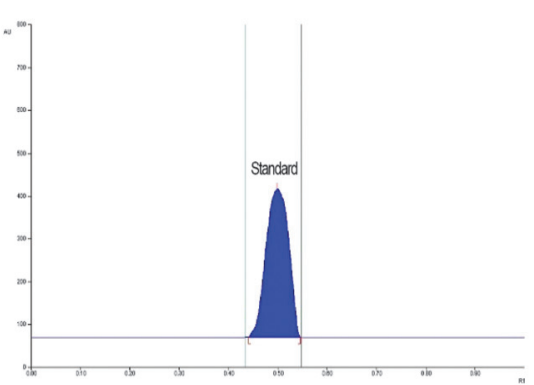

C

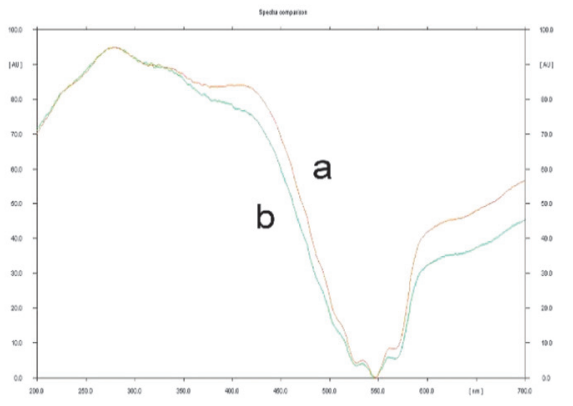

$\mathrm{D}$

Figure 1. A, HPTLC plate after staining, 3D figure of original sample and standard: 1 and 2, original sample; 3 and 4, glycerol standard; B, peak of one sample at $R_{\mathrm{F}} 0.5 ; \mathrm{C}$, peak of one standard at $R_{\mathrm{F}} 0.5 ; \mathrm{D}$, densitometric spectrum analysis of original sample (curve a) and glycerol standard (curve b). (Abbreviation: HPTLC $=$ high-performance thin-layer chromatography)

Table 1. Linear regression, LOD, and LOQ for glycerol

\begin{tabular}{lcccc}
\hline Compound & Regression equation & $r$ & sdv & LOD $(\mu \mathrm{g} / \mathrm{spot})$ \\
\hline $\begin{array}{l}\text { Glycerol } \\
Y=7813.529+1207.682 * X\end{array}$ & 0.99916 & $0.97 \%$ & 0.125 \\
LOD $=$ limit of detection; LOQ $=$ limit of quantification. & & & 0.5 \\
\hline
\end{tabular}

plate $^{f}\left(10 \times 10 \mathrm{~cm}^{2}\right)$ in duplicate. The plate was developed, air dried, and then was sprayed with the chromogenic agent alkaline potassium permanganate $\left(1.5 \mathrm{~g} \mathrm{KMnO}_{4}, 10 \mathrm{~g} \mathrm{~K}_{2} \mathrm{CO}_{3}\right.$, $1.25 \mathrm{~mL} 10 \% \mathrm{NaOH}, 200 \mathrm{~mL}$ tri-distilled water). Following this, the plate was dried with a hair dryer for $3 \mathrm{~min}$ and then cooled to room temperature. A CAMAG TLC scanner $3^{g}$ with the Wincats 1.4.1 software was used to analyze the plate at the reflectance-absorbance wavelength of $276 \mathrm{~nm}$ using a tungsten lamp. The scanning speed was $20 \mathrm{~mm} / \mathrm{s}$, and the data resolution was a $50 \mu \mathrm{m} / \mathrm{step}$.

Refining original sample using silica gel column chromatography. Activated silica gel ${ }^{f}(90 \mathrm{~g}, 200-300$ meshes) was mixed with methylene chloride $(1: 2, w / v)$ and then poured into a chromatography column $(3.0 \times 60 \mathrm{~cm})$. One milliliter (V2) of the original krill sample was applied to the column and eluted with methylene chloride-methanol $(8: 1, \mathrm{v} / \mathrm{v})$. The eluent was collected by fraction sizes of $100 \mathrm{~mL}$, and tentative identification was conducted using the previously described HPTLC method. The fractions containing glycerol

${ }_{\text {Pre-coated silica gel GF } 254 \text { high-performance TLC plates }}$ $\left(10 \times 10 \mathrm{~cm}^{2}\right)$ and silica gel $(200-300$ meshes $)$ were obtained from Haiyang Chemical (Qingdao, Shandong, China).

${ }^{g} \mathrm{~A}$ TLC scanner 3 equipped with the Wincats 1.4 .1 software was purchased from CAMAG (Muttenz, Switzerland). were pooled and dried by rotary evaporation. The residue was weighed and brought to a constant volume with anhydrous ethanol to $5 \mathrm{~mL}$ (V3) and then used for GC-MS analysis and quantification (sample A).

Quantification. A series of glycerol standard solutions $(1 \mu \mathrm{L}$, $2 \mu \mathrm{L}, 4 \mu \mathrm{L}, 5 \mu \mathrm{L}, 6 \mu \mathrm{L}$ ) was spotted on the $\mathrm{GF}_{254}$ HPTLC plate $\left(10 \times 10 \mathrm{~cm}^{2}\right)$ including $1 \mu \mathrm{g}, 2 \mu \mathrm{g}, 4 \mu \mathrm{g}, 5 \mu \mathrm{g}$, and $6 \mu \mathrm{g}$ of glycerol, and a $3 \mu \mathrm{L}$ sample A was spotted on the same plate. The HPTLC separation was executed, and the peak areas were analyzed by Wincats 1.4.1 software to determine the linearity of glycerol detection and to obtain the content of glycerol in sample A. The glycerol content in the Antarctic krill was calculated using the following formula:

$$
Q(\mathrm{mg} / \mathrm{g})=\frac{A \times \mathrm{V} 3}{\mathrm{~V} 2} \times \mathrm{V} 1 \times \frac{1}{M}
$$

where $Q$ is the content of glycerol in dry Antarctic krill, $A$ is the content of glycerol in sample A ( $\mathrm{mg} / \mathrm{g}), \mathrm{V} 3$ is the volume of sample A, and V2 is the volume of original sample added onto the column. V1 is the volume of original sample, and M is the mass of dry Antarctic krill.

Detection sample A by GC-MS. The sample A was analyzed using an Agilent-7890 GC-MS with an Agilent DB-624 series chromatographic column using the following conditions: column temperature was initially $100^{\circ} \mathrm{C}$, maintained for $4 \mathrm{~min}$, 
Table 2. Glycerol contents for repeated sampling of freeze-dried Antarctic krill

\begin{tabular}{lccccccccc}
\hline & Sample 1 & Sample 2 & Sample 3 & Sample 4 & Sample 5 & Sample 6 & Sample 7 & Sample 8 & Mean \pm SD \\
\hline Glycerol $(\mu \mathrm{g} / \mu \mathrm{L})$ in refined sample (sample A) & 1.524 & 1.872 & 1.668 & 1.728 & 1.416 & 1.932 & 1.476 & 1.560 & $1.647 \pm 0.187$ \\
Glycerol $(\mathrm{mg} / \mathrm{g})$ in Antarctic krill & 1.27 & 1.56 & 1.39 & 1.44 & 1.18 & 1.61 & 1.23 & 1.30 & $1.3725 \pm 0.218$ \\
$\mathrm{AU}=$ absorbance unit; SD = standard deviation. & & & & & & & & & \\
\hline
\end{tabular}

Table 3. Glycerol recovery investigation

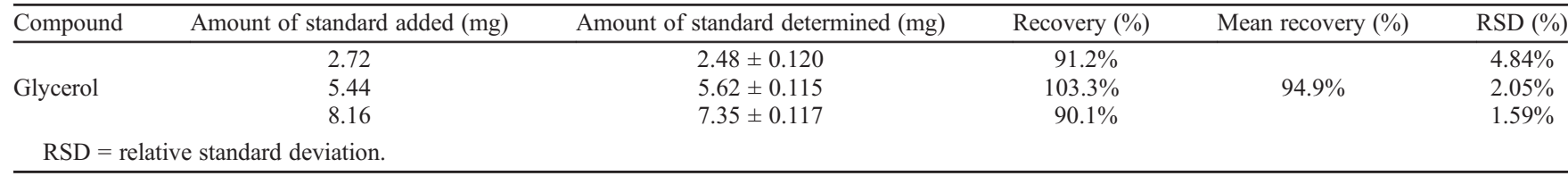
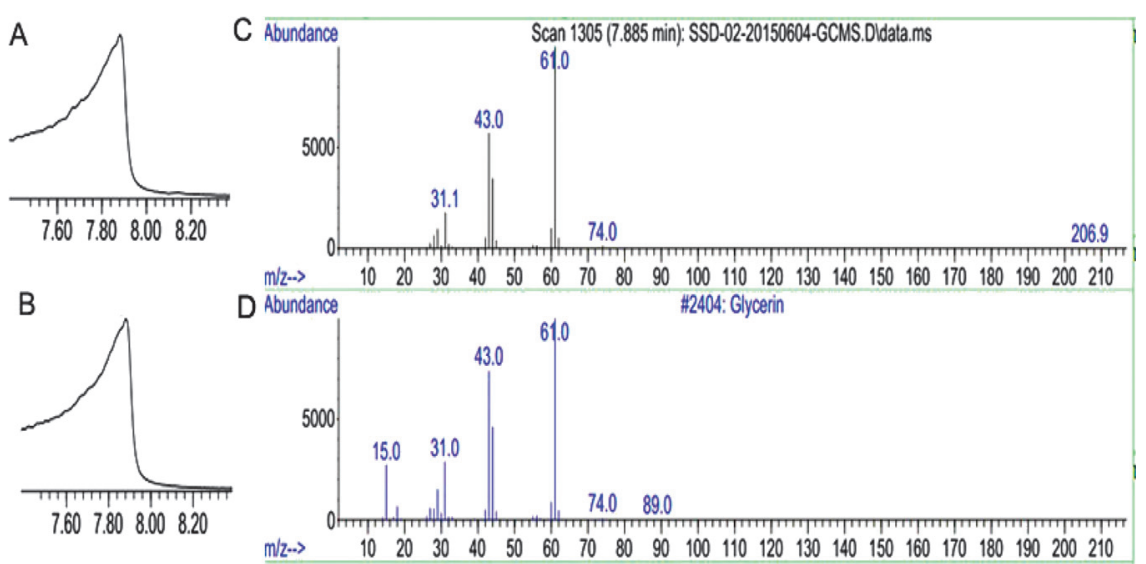

Figure 2. Retention time and mass spectra of glycerol standard and refined sample (sample A); A, retention time of sample A; B, retention time of glycerol standard; C and D, mass spectra of sample A and glycerol standard

and then was gradually increased to $120{ }^{\circ} \mathrm{C}$ at $50{ }^{\circ} \mathrm{C} / \mathrm{min}$, maintained for $10 \mathrm{~min}$, and, finally, increased to $220{ }^{\circ} \mathrm{C}$ at $50{ }^{\circ} \mathrm{C} / \mathrm{min}$, maintained for $6 \mathrm{~min}$. The injector and detector temperatures were set at $200{ }^{\circ} \mathrm{C}$ and $250{ }^{\circ} \mathrm{C}$, respectively. For GC-MS detection, an electron ionization system was used with an ionization energy of $70 \mathrm{eV}$.

Repetition and recovery. Eight repetitions of $40 \mathrm{~g}$ samples of Antarctic krill were extracted, refined, and quantified as previously described. The accuracy of the method was evaluated by a recovery test with three different glycerol concentrations. Three standard solutions of glycerol $(2.72 \mathrm{mg}$, $5.44 \mathrm{mg}, 8.16 \mathrm{mg}$ ) were respectively added to three $1 \mathrm{~mL}$ of the original krill samples (glycerol content $5.44 \mathrm{mg} / \mathrm{mL}$ ). After refining the solutions using silica gel column chromatography, the resulting combined eluents were spotted on the HPTLC plate in triplicate. Chromatograms were developed and scanned as described above. The results were used to calculate the recovery (\%) and the average recovery (\%) for glycerol.

Limit of detection (LOD) and limit of quantification (LOQ). LOD was determined based on the signal-to-noise ratio (3:1) of the HPTLC plate analysis. LOQ was determined based on the signal-to-noise ratio of the HPTLC plate analysis (10:1).

\section{Results and Discussion}

Glycerol is a type of important antifreeze in psychrophile. Chino used TLC to detect glycerol with developing solvents butanol-acetic acid-water $(4: 2: 1, \mathrm{v} / \mathrm{v} / \mathrm{v})$, and ammoniacal silver nitrate was as the color agent [10]. Bansal et al. quantified glycerol in biodiesel by TLC using butanol-water $(1: 1, \mathrm{v} / \mathrm{v})$ with the developing solvents and potassium permanganate solution $\left(0.5 \% \mathrm{KMnO}_{4}\right.$ in $\left.1 \mathrm{~N} \mathrm{NaOH}\right)$ as the chromogenic agent. These authors determined the content of glycerol by analyzing the various areas of the chromatographic spots that corresponded to different gradients of glycerol directly on the plate [6]. This method provided information for the quantification analysis of glycerol, but this method was not found to be accurate. In our experiment, we initially extracted glycerol from the Antarctic krill using ultrasound and then verified its presence using the improved HPTLC method with new developing solvents methylene chloride-methanol $(5: 1, \mathrm{v} / \mathrm{v})$ and alkaline potassium permanganate as chromogenic agent. The glycerol in the Antarctic krill was refined using silica gel column chromatography and then quantified by HPTLC. The results of this analysis are shown in Figure 1. The glycerol in the Antarctic krill was refined using silica gel column chromatography and then quantified by HPTLC. The quantification regression equation was $Y=7813.529+1207.682 * X(r=0.99916)$, and the LOD $(0.125 \mu \mathrm{g} / \mathrm{spot})$ and the LOQ $(0.5 \mu \mathrm{g} / \mathrm{spot})$ are shown in Table 1. The results of repetition are shown in Table 2, and the content of glycerol in Antarctic krill was $1.3725 \pm 0.218 \mathrm{mg} / \mathrm{g}$. The results of recovery are shown in Table 3, and the average percentage recovery of glycerol at three different levels was $94.9 \%$. We proved glycerol structure by GC-MS, and the retention time and mass spectrums are shown in Figure 2.

\section{Conclusions}

The presence of the antifreeze glycerol in Antarctic krill was confirmed by extensive analysis as detailed in this report. The HPTLC method was found to be relatively simple, specific, precise, and accurate for the qualification and quantification glycerol in Antarctic krill. Using this technique, the mean content of glycerol in Antarctic krill was determined to be $1.3725 \pm 0.218 \mathrm{mg} / \mathrm{g}$.

Acknowledgment. The experimental raw materials were supported by the LiaoYu Group Co., Ltd.

\section{References}

1. Ziegler, R. and Wyatt, G. R. Nature 1975, 254, 622. 
2. Bennett, V. A.; Sformo, T.; Walters, K.; Toien, O.; Jeannet, K.; Hochstrasser, R.; Pan, Q.; Serianni, A. S.; Barnes, B. M.; Duman, J. G. J. Exp. Biol 2005, 208, 4467.

3. Clow, K. A.; Ewart, W. R.; Driedzic, K. V. Am. J. Physiol. Regul. Integr. Comp. Physiol 2008, 295, 961.

4. Lane, L. B. Ind. Eng. Chem 2002, 17, 924.

5. Clark, M. S.; Thorne, M. A. S.; Toullec, J. Y.; Meng, Y.; Guan, L. L.; Peck, L. S.; Moore, S. Plos One 2012, 6, e15919.
6. Bansal, K.; Mccrady, J.; Hansen, A.; Bhalerao, K. Fuel 2008, 87, 3369.

7. Rezić, I.; Horvat, A. J. M.; Babić, S.; Kaštelan-Macan, M. Ultrason. Sonochem 2005, 12, 477 .

8. Tang, D. S; Zhang, L.; Chen, H. L.; Liang, Y. R.; Lu, J. L.; Liang, H. L.; Zheng, X. Q. Sep. Purif. Technol 2007, 56, 291.

9. Lima, M. B.; Insausti, M.; Domini, C. E.; Pistonesi, M. F.; Araújo,

M. C. U. D.; Fernández, B. S. Band. Talanta 2012, 89, 21.

10. Chino, H. Nature 1957, $180,606$. 